\title{
Т.В. Шепель
}

\section{СООТНОШЕНИЕ ДОГОВОРНОЙ И ДЕЛИКТНОЙ ОТВЕТСТВЕННОСТИ МЕДИЦИНСКОЙ ОРГАНИЗАЦИИ ПЕРЕД ПАЦИЕНТОМ}

\begin{abstract}
Освещуаются недостаточно исследованные в литературе и неоднозначно решаемые на практике проблемы соотношения договорной и деликтной ответственности медицинской организации: приоритета договорной или деликтной ответственности при причинении вреда пациенту при оказании возмездньх медицинских услуг; природы повышенной ответственности за причинение вреда заказчику возмездных медицинских услуг; одновременного привлечения медициинской организации к договорной и деликтной ответственности.

Ключевые слова: медицинске услуги, договорная и деликтная ответственность.
\end{abstract}

Гражданско-правовая ответственность медицинской организации наступает в соответствии с Гражданским кодексом РФ. Специальное законодательство в сфере охраны здоровья граждан не конкретизирует правила ГК РФ применительно к субъекту ответственности - медицинской организации, а также сфере совершения правонарушения - медицинскому вмешательству. Федеральный закон «Об основах охраны здоровья граждан в Российской Федерации» от 21.11.2011 № 323-Ф3 (в ред. от 31.07.2020) в главе 13 содержит лишь одну ст. 98 отсылочного характера, которая не позволяет определить особенности такой ответственности и ее виды. Нет единства и в правоприменительной практике по спорам о привлечении к гражданскоправовой ответственности медицинских организаций.

В последние годы исследования правоотношений по оказанию медицинских услуг осуществлялись по двум направлениям. Многие цивилисты акцентировали внимание на изучении договора об оказании медицинских услуг (В.Н. Соловьев, 1999; Е.Е. Васильева, 2004; С.В. Нагорная, 2004; А.А. Сироткина, 2004; И.Г. Ломакина, 2006; А.Р. Шаяхметова, 2012 и др.). При этом ответственность за его нарушение или вообще не являлась предметом исследования, или ее характеристика ограничивалась в основном рассмотрением общих условий такой ответственности. Основной целью другой части работ, наоборот, был анализ деликтной ответственности за причинение вреда пациенту (О.А. Пешкова, 1997; Ю.А. Звездина, 2001; Е.В. Муравьёва, 2004; Ю.С. Сидорович, 2005; А.В. Мелихов, 2006 и др.).

В медицинской литературе и литературе по медицинскому праву вопросы ответственности за причинение вреда жизни или здоровью пациента, в том числе гражданско-правовой, освещаются чрезвычайно активно 
(В.Л. Попов, Н.П. Попова, 1999; В.В. Хохлов, Ю.А. Хозяинов, 2000; В.П. Новоселов, 2001; Ю.Д. Сергеев, С.В. Ерофеев, 2001; И.П. Артюхов, К.А. Виноградов, Н.Г. Зайцев, 2002; В.А. Рыков, 2003; С.Г. Стеценко, 2004 и др.). При этом наблюдается широчайший спектр различных трактовок и определений гражданско-правовых категорий ответственности, нередко противоречащих нормам гражданского права или недооценивающих их содержание. В некоторых работах гражданское правонарушение даже не называется в числе оснований правовой ответственности медицинского учреждения. Иногда анализ гражданско-правовой ответственности проводится только со ссылкой на нормы уголовного права, например об обоснованном риске и крайней необходимости. Таким образом, институт гражданско-правовой ответственности медицинской организации перед пациентом продолжает относиться к числу малоисследованных. К числу спорных и не решаемых единообразно в правоприменительной практике вопросов относится соотношение договорной и деликтной ответственности медицинской организации.

Анализ литературы и правоприменительной практики позволяет обозначить отличительные признаки договорной и деликтной ответственности медицинской организации перед пациентом:

1) наличие (отсутствие) договорных отношений между правонарушителем и потерпевшим. Договорная ответственность возникает при неисполнении или ненадлежащем исполнении договора на оказание медицинских услуг. Деликтная же ответственность по общему правилу наступает при отсутствии договора между медицинской организацией и пациентом;

2) императивность норм о деликтной ответственности медицинской организации и диспозитивность норм о ее договорной ответственности;

3) нарушение относительных прав пациента при договорной ответственности и абсолютных - при деликтной ответственности;

4) договорная ответственность медицинской организации перед пациентом возможна лишь в том случае, если не причинен вред его жизни или здоровью; при причинении такого вреда наступает деликтная ответственность. В литературе совершенно обоснованно указывается на то, что причинение вреда жизни, здоровью или имуществу потерпевшего всегда выходит за рамки договора и не может быть предметом договорного регулирования. Поскольку понятия «договор» и «вред» несовместимы, и вред никогда не может быть «договорным», закон выводит обязательства из причинения вреда в связи с исполнением договоров из сферы договорных отношений и применяет к ним нормы гл. 59 ГК РФ о деликтах [1. C. 268-269];

5) значение вины медицинской организации неодинаково: по общему правилу деликтная ответственность наступает независимо от вины при причинении вреда источником повышенной опасности (ст. 1079 ГК РФ). Договорная ответственность при оказании платных медицинских услуг всегда возникает независимо от вины (п. 3 ст. 401 ГК РФ);

6) деликтная ответственность предполагает возмещение вреда в полном объеме (п. 1 ст. 1064 ГК РФ), договорная же ответственность, напротив, 
может быть ограничена возмещением лишь реального ущерба либо только упущенной выгоды (ст. т. 15, 400 ГК РФ);

7) неодинаково юридическое значение вины пациента при привлечении медицинской организации к гражданско-правовой ответственности: при возложении договорной ответственности учитывается любая форма вины кредитора (п. 1 ст. 404 ГК РФ), для деликтной же ответственности юридически значимы только умысел и грубая неосторожность потерпевшего (п. 1, 2 ст. 1083 ГК РФ), простая неосторожность потерпевшего во внимание не принимается;

8) вид ответственности при множественности лиц на стороне медицинской организации зависит от того, о какой ответственности идет речь о договорной или деликтной. При нарушении договора по общему правилу наступает долевая ответственность, при деликтной ответственности - солидарная (ст. 1080 ГК РФ);

9) различны меры договорной и деликтной ответственности медицинской организации. В частности, при деликтной ответственности неустойка не взыскивается. При договорной ответственности может выплачиваться неустойка, предусмотренная договором или законом (п. 5 ст. 28; абз. 3 ст. 30; п. 3 ст. 31 Закона о защите прав потребителей). Компенсация морального вреда является формой только деликтной ответственности.

В советской юридической литературе считалось общепризнанным, что ответственность за вред, причиненный здоровью или жизни пациента при оказании медицинской помощи, является внедоговорной - деликтной [2-5]. Однако в связи с расширением сферы договорного регулирования в медицине правильность таких положений стала подвергаться сомнению. Так, А.А. Сироткина отмечает, что в современной судебной практике России подавляющее число споров о возмещении вреда, причиненного жизни или здоровью гражданина, разрешается на основе норм о деликтах, а нормы о договорной ответственности практически не применяются. По мнению автора, при неисполнении или ненадлежащем исполнении договора об оказании медицинских услуг предпочтение должно отдаваться договорной ответственности. Деликтная ответственность должна применяться при отсутствии договорного обязательства или факта его нарушения [6. С. 147, 148]. Такое же мнение высказано А.А. Богдановой, которая пишет, что при возмездном оказании медицинских услуг следует применять нормы гл. 39 Гражданского кодекса РФ. Вопрос же ответственности в таком случае будет регламентироваться гл. 25 ГК РФ, несмотря на то что действия, направленные на улучшение здоровья пациента, могут не только не привести к излечению, а, наоборот, ухудшить состояние здоровья либо привести к летальному исходу [7. С. 9].

Представляется, что позиция о приоритете договорной ответственности лечебного учреждения не имеет законных оснований. Согласно ст. 1084 ГК РФ вред, причиненный жизни или здоровью гражданина при исполнении договора, по общему правилу возмещается по нормам о деликтах, а не о договорах. Поэтому при причинении вреда пациенту лечебное учреждение 
будет нести ответственность по ст.ст. 1064 и 1068 ГК РФ, если вред причинен медицинским работником при исполнении им трудовых обязанностей. Вывод о приоритете деликтной ответственности медицинской организации при причинении вреда жизни или здоровью пациента при исполнении договора на оказание медицинских услуг преобладает в литературе [1. С. 268$269 ; 8$. С. $81 ; 9$. С. $167 ; 10$. С. 122]. В судебной практике наблюдается такой же подход: независимо от наличия договора на оказание платных медицинских услуг при причинении вреда здоровью или жизни пациента применяются нормы о деликтах $[11,12]$.

Вместе с тем два положения о соотношении деликтной и договорной ответственности медицинской организации нуждаются в более детальном анализе: во-первых, природа предусмотренной договором повышенной ответственности за причинение вреда жизни или здоровью гражданина; во-вторых, вопрос о возможном применении к медицинской организации деликтной и договорной ответственности одновременно.

Согласно ст. 1084 ГК РФ вред, причиненный жизни или здоровью гражданина при исполнении договорных обязательств, а также при исполнении обязанностей военной службы, службы в полиции и других соответствующих обязанностей, возмещается по правилам, предусмотренным этой главой, если законом или договором не предусмотрен более высокий размер ответственности.

В литературе вопрос о природе повышенной ответственности за причинение вреда жизни и здоровью пациента, предусмотренной договором, является спорным. Некоторые авторы признают ее договорной. По мнению Ю.А. Звездиной, признание возможности наступления в ряде случаев договорной ответственности повлечет более внимательное отношение медицинских работников к своим обязанностям. В то же время автор делает оговорку, что договорная ответственность за ненадлежащее оказание медицинских услуг не может быть ни по объему, ни по основаниям меньше деликтной. Договором может быть предусмотрена только повышенная ответственность [13. С. 16-17]. М.Ю. Фёдорова также допускает возможность повышенной договорной ответственности лечебного учреждения за вред, причиненный при оказании медицинской помощи [14. С. 280]. По мнению Е.П. Шевчук, оговорка законодателя о том, что можно применять нормы закона или договора, если он предусматривает более высокий размер ответственности, позволяет пациенту возместить причиненный вред и более эффективно защитить его интересы. Нормы договора могут применяться, если устанавливают более высокий размер ответственности. Например, если в договоре об оказании стоматологических услуг предусмотрен размер неустойки за неисполнение или ненадлежащее исполнение условий договора 100 тыс. руб., а имущественные потери в результате причиненного вреда здоровью составили меньшую сумму, то нормы договора позволят максимально защитить имущественные интересы пациента, нежели нормы гл. 59 ГК РФ. В то же время автор отмечает, что указанная возможность является потенциальной. В медицинской практике подобные 
договоры, как правило, отсутствуют, и более эффективного механизма возмещения пациенту причиненного вреда здоровью при оказании медицинских услуг, чем нормы гл. 59 ГК РФ, пока не существует [9. С. 169].

В литературе высказано и иное мнение. Так, Л.П. Туршук считает, что установленная соглашением сторон (договором) обязанность возместить причиненный вред в большем размере, чем предусмотрено законом, по своей правовой природе является деликтной ответственностью, так как возникает вследствие противоправного повреждения здоровья или причинения смерти гражданину (деликта). Указанное соглашение лишь изменяет деликтное обязательство, но не устанавливает новое договорное правоотношение [15. С. 7]. Мы разделяем данную позицию. Основанием ответственности, несмотря на увеличение ее размера в договоре, продолжает оставаться причинение вреда жизни или здоровью пациента, которое не может расцениваться как нарушение договорных обязательств, оно находится за его рамками. Для анализируемой повышенной ответственности характерны все перечисленные ранее признаки деликтной ответственности. Поэтому договором об оказании медицинских услуг может быть увеличен размер ответственности, но не может изменена ее природа.

Второй вопрос, требующий более детального анализа, - соотношение норм о договорной и деликтной ответственности медицинской организации. По мнению Р.Р. Сафина, гражданский закон исходит из необходимости строгого различия оснований ответственности и по общему правилу не допускает предъявления к одному и тому же ответчику различных судебных требований (исков) по выбору потерпевшего-истца, т.е. так называемой конкуренции исков. Исключением из общего правила он считает правило, установленное для защиты интересов граждан-потребителей в случаях причинения им имущественного вреда, вызванного недостатками проданного им товара. Согласно п. 2 ст. 14 Закона о защите прав потребителей право требовать возмещение вреда, причиненного вследствие недостатков товара (работы, услуги), признается за любым потерпевшим независимо от того, состоял он в договорных отношениях с продавцом (исполнителем) или нет [16. С. 78, 79]. Автор совершенно обоснованно не называет в качестве исключения случаи применения к пациенту, жизни или здоровью которого был причинен вред при исполнении договора об оказании медицинских услуг, норм о деликтах. Деликтная ответственность в таком случае возникает не за нарушение медицинской организацией договорных обязанностей, а за посягательство на абсолютные права - право на жизнь и здоровье.

При исследовании вопроса о соотношении договорной и деликтной ответственности медицинской организации перед пациентом в литературе, как правило, не акцентируется внимание на одновременном применении к медицинской организации норм о договорах и о деликтах. Например, Е.П. Шевчук в своей работе ссылается на решение суда о привлечении лечебного учреждения к договорной ответственности в виде взыскания неустойки и возмещения убытков в связи с тем, что после офтальмологи- 
ческой операции у пациентки не произошло полного восстановления нормального зрения, вместо близорукости возникла дальнозоркость. Она полагает, что в рассматриваемом случае исполнитель медицинской услуги нарушил условие договора о качестве ее оказания, но вред здоровью в процессе ее оказания не возник, поэтому применимы нормы договора и диспозитивные нормы закона, поскольку ответственность вытекает из самого договора [9. С. 165]. Вместе с тем в анализируемом решении суд указал на необходимость компенсации истице и морального вреда, которая никак не может быть отнесена к форме договорной ответственности, однако автор не комментирует решение в этой части. Далее Е.П. Шевчук приводит еще один пример договорной ответственности медицинской организации - за оказание стоматологической услуги ненадлежащего качества. К числу мер договорной ответственности, кроме возмещения убытков и уплаты процентов за пользование чужими денежными средствами, без какихлибо пояснений отнесена компенсация морального вреда [Там же. С. 168]. А.В. Плотникова к мерам ответственности по договору на оказание медицинских услуг также относит компенсацию морального вреда [17].

Представляется, что в названных случаях речь идет о привлечении медицинской организации не только к договорной, но и к деликтной ответственности в виде компенсации морального вреда. Несомненно, компенсация морального вреда является формой деликтной ответственности, нормы о ней расположены в $\$ 4$ гл. 59 ГК РФ. Признаки, присущие деликтной ответственности, свойственны и компенсации морального вреда. Однако в судебных решениях о привлечении исполнителя медицинских услуг к договорной ответственности на этом внимание не акцентируется- компенсация морального вреда называется в числе форм договорной ответственности со ссылкой, как правило, на Закон о защите прав потребителей [18]. При таком подходе размываются различия в условиях ответственности медицинской организации за нарушение договора об оказании возмездных медицинских услуг и деликтной ответственности в форме компенсации морального вреда. Согласно п. 3 ст. 401 ГК РФ, а также п. 4 ст. 13 Закона о защите прав потребителей договорная ответственность в таких случаях возникает независимо от вины, освобождение от ответственности возможно лишь при неисполнении обязательств или их ненадлежащем исполнении вследствие непреодолимой силы. Компенсация же морального вреда допускается, по общему правилу, только при наличии вины причинителя вреда (абз. 2 ст. 151 ГК РФ).

Таким образом, можно сделать следующие выводы.

1. Договорная ответственность медицинской организации возникает лишь в том случае, если при оказании возмездных медицинских услуг не причинен вред жизни или здоровью пациента. При причинении такого вреда может наступить только деликтная ответственность, несмотря на наличие договорных отношений между медицинской организацией и пациентом.

2. Если договором об оказании медицинских услуг предусмотрена повышенная ответственность за причинение вреда пациенту, она продолжает 
оставаться деликтной, договором изменяется лишь размер подлежащего возмещению вреда.

Распространенный в судебной практике и литературе подход к отнесению компенсации морального вреда к формам договорной ответственности исполнителя возмездных медицинских услуг (при отсутствии вреда, причиненного жизни или здоровью), наряду с возмещением убытков и взысканием неустойки, приводит к игнорированию различий в условиях гражданско-правовой ответственности. Условия договорной ответственности в таких случаях должны определяться в соответствии с п. 3 ст. 401 ГК РФ и п. 4 ст. 13 Закона о защите прав потребителей, а условия деликтной ответственности за причиненный моральный вред - в соответствии с абз. 2 ст. 151 ст. 1100 ГК РФ.

\section{Лumepamypa}

1. Рабец А.М., Еремин Г.Б., Мохов Д.Е., Серёгина И.Ф., Маймулов В.Г. Права потребителей услуг в здравоохранении. М. : ОЛМА Медиа Групп, 2010. 318 с.

2. Майданик Л.А. Ответственность медицинских учреждений за ненадлежащее лечение // Советская юстиция. 1967. № 16. С. 12-13.

3. Ярошенко К.Б. Имущественная ответственность лечебных учреждений за вред, причиненный их работниками // Вопросы государства и права. Минск : Изд-во БГУ, 1970. Вып. 2. С. 247-254.

4. Малеин Н.С. Гражданский закон и права личности в СССР. М. : Юрид. лит., $1981.215 \mathrm{c}$.

5. Савицкая А.Н. Возмещение ущерба, причиненного ненадлежащим врачеванием. Львов : Вища школа, 1982. 195 с.

6. Сироткина А.А. Договор оказания медицинских услуг: особенности правового регулирования : дис. ... канд. юрид. наук. М., 2004. 173 с.

7. Богданова А.А. Соотношение договорной и деликтной ответственности вследствие ненадлежащего оказания медицинских услуг // XXI Царскосельские чтения : материалы междунар. науч. конф., 25-26 апр. 2017 г. СПб. : ЛГУ им. А.С. Пушкина, 2017. T. III. C. 9-13.

8. Ситдикова Л.Б. Обязательства по оказанию медицинских услуг: соотношение договорной и деликтной ответственности // Современное право. 2016. № 7. С. 80-84.

9. Шевчук Е.П. Соотношение договорной и деликтной ответственности в обязательствах по возмещению вреда здоровью, причиненного при оказании медицинских услуг // Вестник Забайкальского университета. 2014. № 7 (110). С. 163-169.

10. Вильгоненко И.М., Гагиева Н.Р., Белокопытова Н.Ю. Особенности возмещения вреда, причиненного ненадлежащим оказанием медицинских услуг // Вестник Волжского университета им. В.Н. Татищева. 2018. № 4. Т. 2. С. 119-126.

11. Обзор судебной практики Верховного Суда Российской Федерации № 2 (2019) : утв. Президиумом ВС РФ 17.07.2019. URL: http://www.consultant.ru/document/ cons_doc_LAW_329423/

12. Справка о результатах обобщения судебной практики рассмотрения судами Иркутской области гражданских дел, связанных с оказанием медицинских услуг ненадлежащего качества, причинением вреда здоровью потерпевшего либо смертью потерпевшего в результате неправильного лечения, несвоевременного оказания медицинской помощи за 2016-2017 годы от 14.06.2018 (с изм. от 8.08.2018). URL: http://oblsud.irk.sudrf.ru/ modules.php?name=docum_sud\&id=599 
13. Звездина Ю.А. Гражданско-правовая ответственность за причинение вреда при оказании медицинских услуг : автореферат дис. ... канд. юрид. наук. СПб., 2000. 20 с.

14. Фёдорова М.Ю. Медицинское право : учеб. пособие для вузов. М. : ВЛАДОС, 2003. $320 \mathrm{c}$.

15. Туршук Л.Д. Гражданско-правовая ответственность за вред, причиненный жизни или здоровью гражданина : автореферат дис. ... канд. юрид. наук. СПб., 2011. 26 с.

16. Сафин Р.Р. Соотношение договорной и внедоговорной ответственности // Социально-экономические и технические системы: исследование, проектирование, оптимизация. 2016. № 1 (68). С 73-80.

17. Плотникова А.В. Правовые последствия нарушения договора возмездного оказания медицинских услуг // Концепт : научно-методический электронный журнал. 2019. № 4 (апрель). С. 172-177 URL: http://e-koncept.ru/2019/193024.htm

18. О защите прав потребителей : закон РФ от 07.02.1992 № 2300-1 (ред. от 24.04.2020). URL: http://www.consultant.ru/document/Cons_doc_LAW_305/5311cc4c47a088 e5ebc6a23b15f59fa70221f8ce/

Shepel Tamara V., Novosibirsk National Research State University (Novosibirsk, Russian Federation)

CORRELATION OF CONTRACTUAL AND TORTIOUS LIABILITY OF A HEALTHCARE ORGANISATION TO A PATIENT

Keywords: health services, contractual and tort liability.

\section{DOI: $10.17223 / 22253513 / 38 / 15$}

The Civil Code of the Russian Federation and legislation in the sphere of health care do not contain norms about the civil liability of a medical organisation to a patient. The issues of the correlation between these types of liability remain under-researched in the literature. There is no uniformity in judicial practice in resolving disputes in this area.

The analysis of the literature and practice allows us to identify the distinctive features of contractual and tort liability of medical organisations. They include the imperative nature of norms on tort liability and dispositive nature of norms on contractual liability; contractual liability of a medical organisation to a patient is possible only if no harm to life or health is inflicted upon it - when such harm is inflicted, tort liability arises. The medical organisation's guilt or the patient's guilt in imposing contractual or non-contractual liability on a medical organisation is not the same. As a general rule, where there is a plurality of persons on the side of a medical organisation, joint and several liability arises in the event of non-contractual liability. The forms of contractual and non-contractual liability are different.

It is generally accepted in the legal literature that liability for harm to a patient's health or life in the provision of paid medical services is in tort. However, due to the expanding scope of contractual regulation in medicine, the correctness of such provisions has come into question. It seems that the position on the priority of contractual liability of a medical institution has no legitimate basis (Art. 1084 of the Civil Code of the Russian Federation). In court practice, regardless of the existence of a contract for the provision of paid medical services, in case of harm to the patient's health or life, the rules on torts are applied.

The nature of increased liability for causing harm to a citizen's life or health stipulated by the contract is disputed in the literature. It appears that the contract for the provision of medical services may increase the amount of liability but may not change its nature, it remains a tort.

As a rule, the issue of possible application of tort and contractual liability to a medical organisation at the same time is not specifically discussed in the literature. In court decisions holding a healthcare provider contractually liable, compensation for moral damage is referred to as a form of contractual liability along with compensation for damages and payment of 
a penalty. This approach blurs the distinction in terms of contractual liability of a medical organisation and tort liability in the form of compensation for moral harm. Contractual liability arises irrespective of fault (paragraph 3 of Article 401 of the Civil Code of the Russian Federation); compensation for moral harm is allowed, as a general rule, only in the presence of the fault of the person who caused the harm (paragraph 2 of Article 151 of the Civil Code of the Russian Federation). The terms of liability in such cases must be determined with due regard to the above rules.

\section{References}

1. Rabets, A.M., Eremin, G.B., Mokhov, D.E., Seregina, I.F. \& Maymulov, V.G. (2010) Prava potrebiteley uslug $v$ zdravookhranenii [Consumer rights in healthcare]. Moscow: OLMA Media Grupp.

2. Maydanik, L.A. (1967) Otvetstvennost' meditsinskikh uchrezhdeniy za nenadlezhashchee lechenie [Responsibility of medical institutions for improper treatment]. Sovetskaya yustitsiya. 16. pp. 12-13.

3. Yaroshenko, K.B. (1970) Imushchestvennaya otvetstvennost' lechebnykh uchrezhdeniy za vred, prichinennyy ikh rabotnikami [Property liability of medical institutions for harm caused by their employees]. Voprosy gosudarstva i prava. 2. pp. 247-254.

4. Malein, N.S. (1981) Grazhdanskiy zakon i prava lichnosti v SSSR [Civil Law and Individual Rights in the USSR]. Moscow: Yurid. lit.

5. Savitskaya, A.N. (1982) Vozmeshchenie ushcherba, prichinennogo nenadlezhashchim vrachevaniem [Compensation for damage caused by improper treatment]. Lvov: Vishcha shkola.

6. Sirotkina, A.A. (2004) Dogovor okazaniya meditsinskikh uslug: osobennosti pravovogo regulirovaniya [Contract for the provision of medical services: specificity of legal regulation]. Law Cand. Diss. Moscow.

7. Bogdanova, A.A. (2017) Sootnoshenie dogovornoy i deliktnoy otvetstvennosti vsledstvie nenadlezhashchego okazaniya meditsinskikh uslug [The ratio of contractual and tort liability due to improper provision of medical services]. XXI Tsarskosel'skie chteniya [The 21st Tsarskoye Selo Readings]. Proc. of the International Conference. April 25-26, 2017. Vol. 3. St. Petersburg: A.S. Pushkin Leningrad State University. pp. 9-13.

8. Sitdikova, L.B. (2016) Obligations for healthcare: correlation of contractual and tort liability. Sovremennoe pravo. 7. pp. 80-84. (In Russian).

9. Shevchuk, E.P. (2014) Ratio of contractual and delictual responsibility in obligations for compensation of harm to the health done at rendering medical services. Vestnik Zabaykal'skogo universiteta. 7(110). pp. 163-169. (In Russian).

10. Vilgonenko, I.M., Gagieva, N.R. \& Belokopytova, N.Yu. (2018) Features of compensation of harm, caused by improper provision of medical services. Vestnik Volzhskogo universiteta im. V.N. Tatishcheva - Vestnik of Volzhsky University after V.N. Tatishchev. 4(2). pp. 119-126. (In Russian).

11. Russian Federation. (2019) Obzor sudebnoy praktiki Verkhovnogo Suda Rossiyskoy Federatsii № 2 (2019): utv. Prezidiumom VS RF 17.07.2019 [Review No. 2 (2019) of judicial practice of the Supreme Court of the Russian Federation: approved by the Presidium of the the Supreme Court of the Russian Federatio on July 17, 2019]. [Online] Available from: http://www.consultant.ru/document/cons_doc_LAW_329423/

12. Irkutsk Regional Court. (2018) Summarized judicial practice of examining civil cases related to the provision of medical services of inadequate quality, harm to the victim's health or death of the victim as a result of improper treatment, untimely provision of medical care by the courts of Irkutsk Region for 2016-2017 from June 14, 2018 (as amended of August 8, 2018). [Online] Available from: http://oblsud.irk.sudrf.ru/modules.php?name=docum_ sud\&id=599. (In Russian). 
13. Zvezdina, Yu.A. (2000) Grazhdansko-pravovaya otvetstvennost' za prichinenie vreda pri okazanii meditsinskikh uslug [Civil liability for causing harm in the provision of medical services]. Abstract of Law Cand. Diss. St. Petersburg.

14. Fedorova, M.Yu. (2003) Meditsinskoe pravo [Medical Law]. Moscow: VLADOS.

15. Turshuk, L.D. (2011) Grazhdansko-pravovaya otvetstvennost' $z a$ vred, prichinennyy zhizni ili zdorov'yu grazhdanina [Civil liability for harm caused to the life or health of a citizen]. Abstract of Law Cand. Diss. St. Petersburg.

16. Safin, R.R. (2016) The ratio of contractual and non-contractual liability. Sotsi-al'noekonomicheskie i tekhnicheskie sistemy: issledovanie, proektirovanie, optimizatsiya. 1(68). pp. 73-80. (In Russian).

17. Plotnikova, A.V. (2019) Legal consequences of paid medical services contract violation. Kontsept. 4. pp. 172-177. [Online] Available from: http://e-koncept.ru/2019/193024.htm. (In Russian).

18. Russian Federation. (1992) $O$ zashchite prav potrebiteley: zakon RF ot 07.02.1992 № 2300-1 (red. ot 24.04.2020) [On protection of consumer rights: Law No. 2300-1 of the Russian Federation dated February 7, 1992 (as amended on 24.04.2020).]. [Online] Available from: http://www.consultant.ru/document/Cons_doc_LAW_305/5311cc4c47a088e5ebc6a23 b15f59fa70221f8ce/ 